\title{
Directed Diffusion: Features, Current Developments, Issues and Analysis
}

\author{
Umesh Rawat ${ }^{1}$ \\ 1 M.Tech Student, Computer Science and \\ Engineering \\ The Technological Institute of Textile and \\ Sciences, Bhiwani,
}

\author{
Mukesh Sharma ${ }^{2}$ \\ Phd,2 Associate Professor, Department of \\ Computer Science and Engineering \\ The Technological Institute of Textile and \\ Sciences, Bhiwani,
}

\begin{abstract}
Directed diffusion (DD) is typical data-centric protocol for wireless sensor networks, all nodes in a directed diffusion based network are application-aware, and this enables diffusion to achieve energy savings by selecting empirically good paths and by caching and processing data in-network But at the beginning of routing being established, interest must be flooded throughout the network, Directed Diffusion Protocol (DDP) which could meet the features of WSN, such as data-oriented, many-to-one transmissions and low energy costs, together with data aggregation mechanisms which emphasized on cascading timeouts, to eliminate the redundancy caused by the transmission of large amounts of data. This paper presents the description of DD protocol and current developments including the view for which one is best.
\end{abstract}

Keywords:- Directed Diffusion, WSN Protocols

\section{INTRODUCTION}

In recent years, wireless sensor networks have attracted more and more related researchers for its advantages. Sensor nodes are usually low-power and non-rechargeable. The integrity of the original networks will be destroyed and other nodes will have more business burden for data transmission if the energy of some certain nodes deplete. The key issue of sensor network research is to balance the energy consumption of all sensor nodes and to minimize the impact of random failure of sensor nodes or random attacks to sensor nodes on the entire network. A number of routing protocols have been proposed for sensor networks [1]. Directed Diffusion [2] is one of the energy efficient routing protocols that have been proposed. The directed diffusion algorithm does not use any mechanism to protect the nodes from outsider attacks. This paper presents a brief work which had done in the Directed Diffusion protocol and it also conclude which approach is better as per the requirement of applications.

\section{DESCRIPTION OF DIRECTED DIFFUSION}

In the description of Directed Diffusion we will study its literature and statically analysis as follows

\subsection{Directed Diffusion Protocol}

Directed diffusion is a typical data-centric protocol for WSN which laid the pivotal foundation for wireless network routing design and is leading the way in data centric protocol design. However, in this protocol interest messages are diffused to all sensor nodes by the way of flooding, which will generate a large number of redundant messages, so $\mathrm{DD}$ has a poor performance [3]. The clustering idea in LEACH was introduced to it, and some protocols based on clustering were proposed such as IDD DDBC. Directed Diffusion has been developed after SPIN and has become a breakthrough in DataCentric routing. Directed diffusion finds routes from multiple sources to a single destination that allows in-network consolidation of redundant data (Aggregation). Directed diffusion is a typical query-based routing, it consists of several elements. Data is named using attribute-value pairs. A sensing task is disseminated throughout the sensor network as an interest for named data. This dissemination sets up gradients within the network designed to "draw" events (i.e., data matching the interest). Events start flowing towards the originators of interests along multiple paths. The sensor network reinforces one, or a small number of these paths.

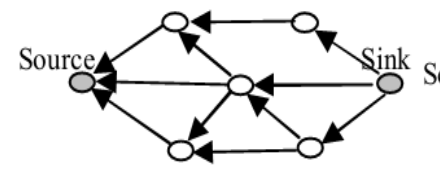

(a) Propagate interest

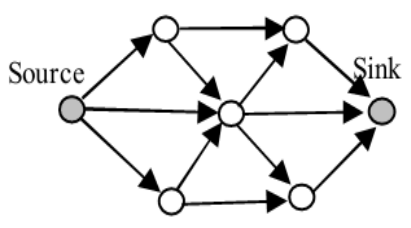

(b) Set up gradients

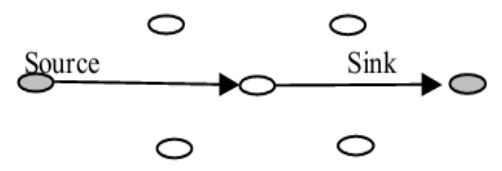

(c) Send data and path reinforcement

\section{Fig.1 A simplified schematic for directed diffusion}

Directed diffusion is data-centric in that all communication is for named data. All nodes in a directed diffusion-based network are application-aware. This enables diffusion to achieve energy saving by selecting empirically good paths and by caching and processing data in network. But in directed diffusion, there is interest flooding throughout the sensor network when the routing is established, so its overhead of energy and time is large. For this reason we introduce Improved Directed Diffusion (IDD).

\subsection{Directed Diffusion Architecture}

Routing protocols for sensor networks should be energy efficient and flexible for topological changes and network scalability. In addition, they should work with an attributebased addressing scheme and a data-centric (DC) routing scheme. The DC routing scheme has come into being with the advent of sensor networks and is contrary to the addresscentric (AC) conventional routing scheme. Routing protocols 
have been done to date and they can be classified into three types of schemes as follows:

1. Flat routing: Flooding, Gossiping, Directed Diffusion, SPIN etc.

2. Hierarchical routing: LEACH, TEEN, etc.

3. Location-based routing: GEAR, MECN, etc.

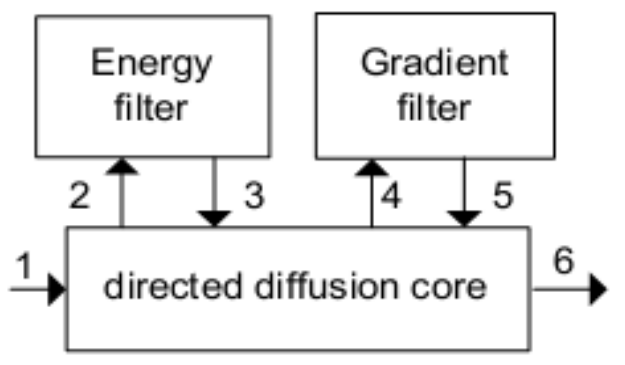

Fig.2 Data Flow

1. Reception of Exploratory data.

2. Energy filter stores the exploratory data locally and sets up a timer.

3,4.Energy filter selects on e message in the message entry and sends it to the Gradient filter.

5.Gradient filter forwards the message to the neighbors that have interest on the message.

6.Directed diffusion core sends the message to the network. This will set up the reinforced paths to deliver the message to its destination.

Directed Diffusion Protocol Family

\begin{tabular}{|l|l|l|}
\hline Protocol & Sink & Source \\
\hline $\begin{array}{l}\text { Two Phase } \\
\text { Pull }\end{array}$ & $\begin{array}{l}\text { Interest* (every } \\
\text { interest interval) } \\
\text { Positive } \\
\text { reinforcement } \\
\text { (response to exp. } \\
\text { data) }\end{array}$ & $\begin{array}{l}\text { Exploratory } \\
\text { data* } \\
\text { (every } \\
\text { exploratory } \\
\text { interval) (Data } \\
\text { rate defined by } \\
\text { app.) }\end{array}$ \\
\hline $\begin{array}{l}\text { One phase } \\
\text { Pull }\end{array}$ & $\begin{array}{l}\text { Interest* pull } \\
\text { (every interest } \\
\text { interval) }\end{array}$ & $\begin{array}{l}\text { dasitive } \\
\text { Reinforcement } \\
\text { (response to exp } \\
\text { data) }\end{array}$ \\
\hline Push & $\begin{array}{l}\text { Exploratory } \\
\text { data* } \\
\text { (every } \\
\text { exploratory } \\
\text { interval) }\end{array}$ \\
\hline
\end{tabular}

\subsubsection{Two phase Pull Diffusion}

Simple directed diffusion is also called two-phase pull diffusion where sink seeks out data sources using interest, and then sources search to find the best possible path back to sink. Interests must be flooded throughout the network to find any data sources resulting in extra high overhead for maintaining the routes. Two-phase pull [4] works well for applications having small number of sinks and not suitable for large number of sinks being used, because all sensors actively send interests and maintain gradients to all other sensors even though nothing is detected. In two-phase pull, data sinks are active, sending out interests, while sources are passive until interests arrive. A simplified schematic for directed diffusion are as follows

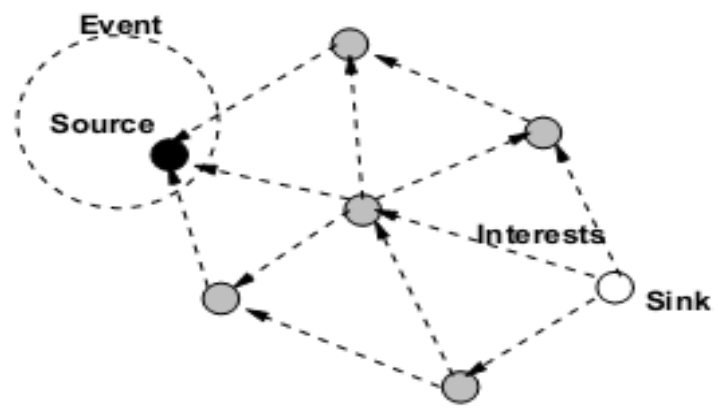

(a) Interested Propagation

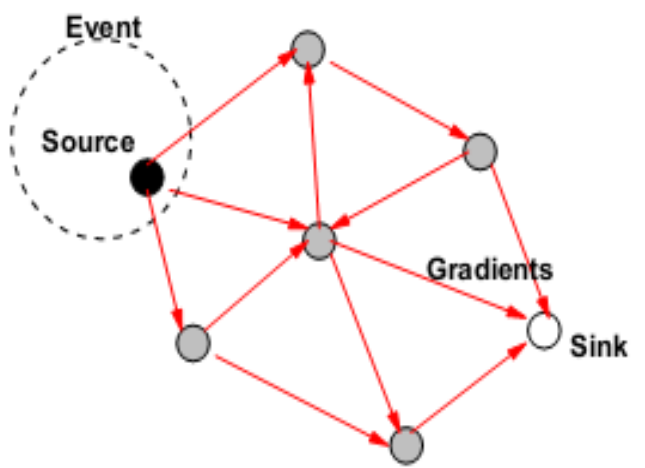

(b) Initial gradients setup

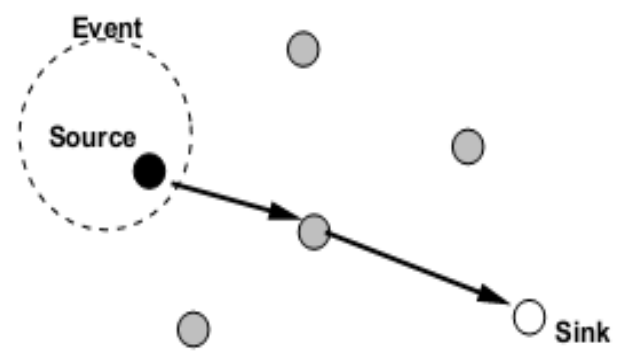

(c) Data delivery along reinforced path

\section{FIG.3 Directed Diffusion Mechanism}

\subsubsection{Flow diagram of Sequenced \& Threshold DD routing Schema}

Most of a sensor network's routing protocols tend to take one particular path between source nodes and sink nodes, and the selected path can hardly be changed until some sensor nodes on the communication path lose their energy or go out of order. Thus, if monitored events occur repeatedly, then route sensor nodes' energy consumption increases continuously more than that of any other sensor nodes. 


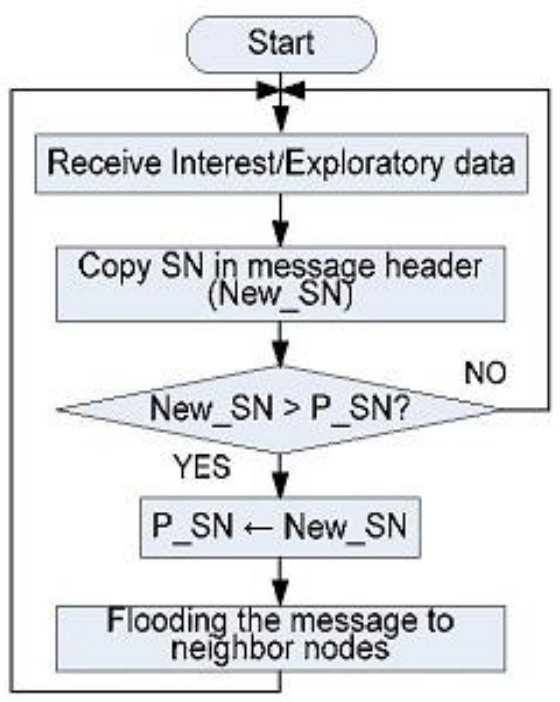

Fig4. Flow diagram of Sequenced DD routing Schema

Finally, if the remaining energy is higher than the threshold TI, this sensor node should play a routing role in any case. If a Sensor node is a source node, however, then the source node should always send the interest message to its neighbor, without regard for its remaining energy.

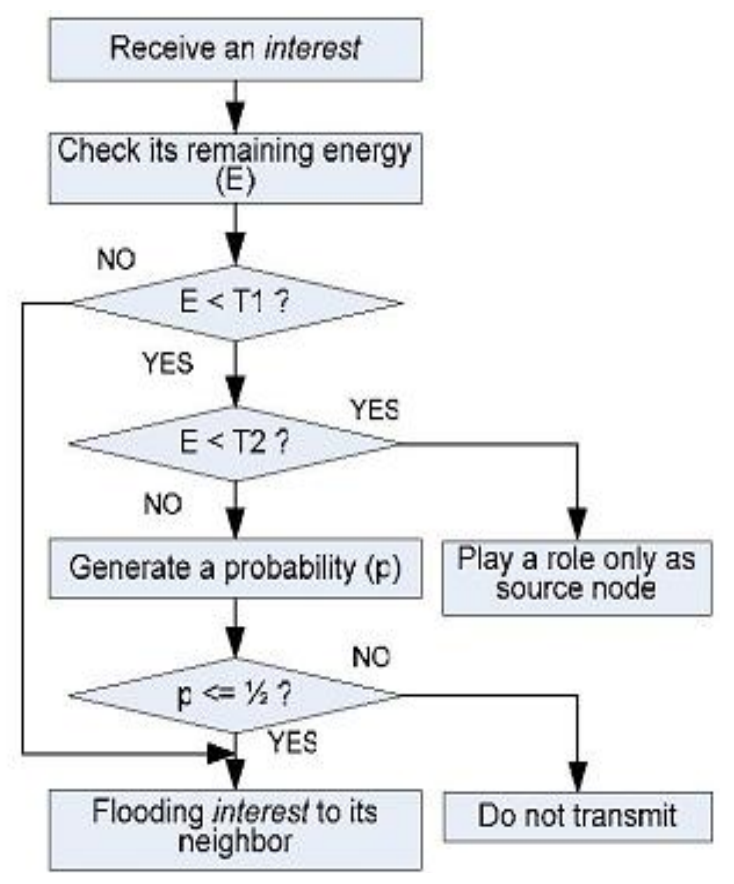

Fig5. Flow diagram of threshold DD routing scheme

\subsection{Discussion of Directed Diffusion \\ Protocol}

In the directed diffusion protocol, a request for data from an initiator is broadcast in the network, and the positive answers from the sensors are forwarded back to the requester using a shortest path. For any node, an initiator is identified by a gradient field, which specifies the neighboring node through which the request has been received. An addition to the protocol, we allow any number of initiators and any number of requests per initiator.

\section{Real time Directed Diffusion Protocol}

The two-phase pull model of directed diffusion may be easily extended to support real-time data flows. The primary additions to diffusion required for RTDD [5] are a prioritized queue and a scheduling policy. We have developed both static and dynamic scheduling policies for RTDD equivalent to SVM and DVM in RAP. In addition, we have extended the protocol to compute priority without requiring each node to possess location information.

Several time synchronization protocols for sensor networks have been proposed [6], so this requirement is quite feasible. Like the location-based protocols, two versions of the relative time-based algorithm are also defined. The priority may be calculated statically at the source (SRT) or dynamically at each hop (DRT). In the former case, the priority is computed according to Equation 1 .

$$
\mathrm{P}=\frac{\text { Tsink }- \text { Tsource }}{\text { Tdeadline }}
$$

In this equation, $\mathrm{T}_{\text {Source }}$ is the time the exploratory data packet was sent from the source, $\mathrm{T}_{\text {Sink }}$ is the time the reinforcement message was sent from the sink, and $\mathrm{T}_{\text {deadline }}$ is the deadline of the data flow (in units of time, not a timestamp). The timebased approach computes a priority value which is a ratio of times.

In the dynamic case, the priority of a packet will be recalculated at each hop. If the source timestamps exploratory data messages and the sink timestamps reinforcement messages, then each node along the reinforced path can calculate the time delay from itself to the sink. Each node along the data path must cache the delay between the most recent exploratory data and the reinforcement message in order to support distance awareness. Data messages must also be time stamped by the source so that intermediate nodes can calculate elapsed time for a given packet. The elapsed time is subtracted from the deadline to gauge the deadline urgency of the message.

DRT calculates priority using Equation 2.

$$
\mathrm{P}=\frac{\mathrm{Tsin} k-\mathrm{Ti}}{\text { Tdeadline }- \text { Telapsed, } \mathrm{i}}
$$

In this case, Ti represents the time the exploratory data packet was sent from the intermediate node $i$, Tsink is the time the reinforcement message was sent from the sink, Tdeadline is the deadline of the data flow, and Telapsed,i is the time elapsed in sending the data packet to hop i. Elapsed time, Telapsed,i, is computed as

Telapsed, $\mathbf{i}=$ Tnow - Tdata where Tnow is the current time and Tdata is the time the data packet was sent from the source. To simplify the protocol we estimate the delay between intermediate node and sink (the numerator of Equation 2) as the total end-to-end delay minus the elapsed time, or more formally, $\mathbf{T}$ sink $-\mathbf{T i} \approx \mathbf{T}$ sink- Tsource Telapsed,i . Thus, Equation 2 becomes

$$
\mathrm{P}=\frac{\text { Tsink }- \text { Tsource }- \text { Telapsed,i }}{\text { Tdeadline }- \text { Telapsed,i }}
$$

The time-based techniques achieve the same end, packet prioritization based on both distance and deadline, but do so without the strong localization requirement of SVM and DVM. The numerators in Equations 1 and 2 correlate to distance awareness and the denominators encapsulate deadline 
awareness. Although our location-free design requires more communication overhead than the location-based algorithms, the communication is essentially free since the timestamp information is piggybacked on the packets involved in diffusion's two-phase path discovery protocol. No additional packets are required, only a slightly increased packet size. This trade-off may be advantageous for applications where location information is not available.

\section{ISSUES RELATED WITH DIRECTED DIFFUSION}

The possible attacks on directed diffusion protocol can be classified under:

1. Denial of Service attacks

2. Modification and spoofing of routing information.

3. Dropping or selective forwarding of data.

\section{Denial of Service attacks}

The simplest form of the denial of service attack would require an attacker to deploy a malicious node with a powerful transmitter and a large battery power. This would enable the attacker to jam the communications in the entire sensor network with his powerful transmitter. A normal malicious node would only be able to jam the communication link in its immediate vicinity

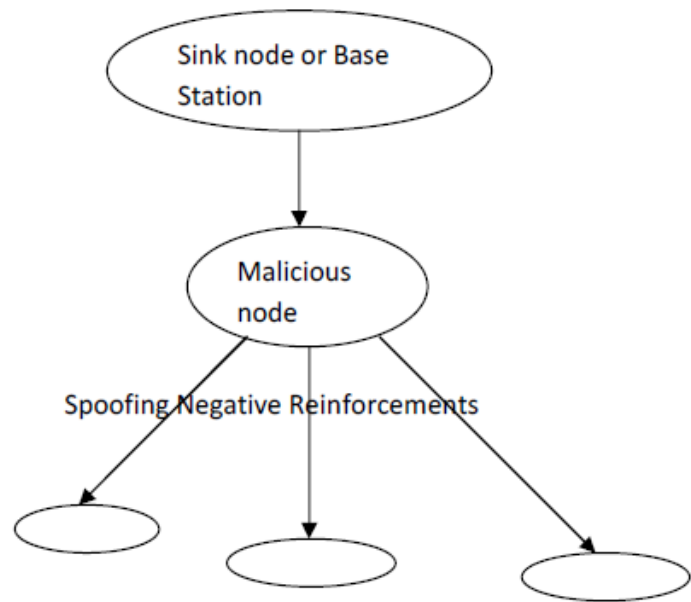

Fig4: Simple DOS attack

\section{Modification and spoofing of routing information}

In Directed Diffusion the routing is done on the basis of interest dissemination and the corresponding gradient establishment [7]. If a malicious node receives interests from the base station, it could replay the interest with itself listed as the base station. This would enable the malicious node to receive a copy of the events, which are sent to the base station.

\section{Dropping or selective forwarding of data}

Most sensor networks are multi hop networks [8]. These networks rely on all the nodes to correctly forward the messages. In this scenario a malicious node could drop or selectively forward only certain messages. If a malicious node drops all messages, it would be as good as the node not being present in the network. The sensor network is designed to adapt to this. But a more severe form of this attack would be if a malicious node selectively forwards only certain messages. With the spoofed positive and negative reinforcements discussed in the previous section, we saw how a malicious node can successfully include itself in the path of data flow. This now makes selective forwarding trivial. The malicious node can now forward only certain messages and suppress the rest.

\section{CURRENT DEVELOPMENTS}

The current developments which done in area of directed diffusion in recent years is summarized as follows:-

\begin{tabular}{|c|c|c|c|c|}
\hline $\begin{array}{l}\text { S } \\
\text { R. } \\
\text { N } \\
\text { O. }\end{array}$ & AUTHOR & $\begin{array}{l}\text { Year/Publi } \\
\text { cation }\end{array}$ & EFFECTS & DESCRIPTION \\
\hline 1. & $\begin{array}{l}\text { Shoushen } \\
\text { g Zhao }\end{array}$ & $\begin{array}{l}2007, \\
\text { IEEE }\end{array}$ & $\begin{array}{l}\text { Energy } \\
\text { Efficiency }\end{array}$ & $\begin{array}{l}\text { The protocol considers the communication } \\
\text { cost, average remaining energy, minimum } \\
\text { remaining energy and node connectivity. It } \\
\text { selects a routing path with the least cost } \\
\text { function. Since the proposed protocol } \\
\text { consumes less energy (approximately } 86 \% \\
\text { of the average dissipated energy in the } \\
\text { original directed diffusion). }\end{array}$ \\
\hline 2. & $\begin{array}{l}\text { Ramesh } \\
\text { Govindan }\end{array}$ & $\begin{array}{l}\text { 2003,IEE } \\
\text { E }\end{array}$ & $\begin{array}{l}\text { Explore } \\
\text { and } \\
\text { evaluate } \\
\text { DD }\end{array}$ & $\begin{array}{l}\text { Directed diffusion has the potential for } \\
\text { significant energy efficiency. Even with } \\
\text { relatively unoptimized path selection, it } \\
\text { outperforms an idealized traditional data } \\
\text { dissemination scheme like omniscient } \\
\text { multicast, diffusion mechanisms are stable } \\
\text { under the range of network dynamics } \\
\text { considered in this paper. }\end{array}$ \\
\hline 3. & Jielei Yu & $\begin{array}{l}2010, \\
\text { IEEE }\end{array}$ & $\begin{array}{l}\text { Directed } \\
\text { Diffusion } \\
\text { based on } \\
\text { clustering } \\
\text { and inquiry } \\
\text { (DDBCI) }\end{array}$ & $\begin{array}{l}\text { The cluster head nodes can avoid diffusing } \\
\text { the interest messages into the cluster } \\
\text { blindly. DDBCI protocol effectively } \\
\text { reduces redundant information spread and } \\
\text { saves the energy of cluster head nodes and } \\
\text { cluster member nodes. }\end{array}$ \\
\hline 4. & $\begin{array}{l}\text { Mehdi } \\
\text { Mirfattah } \\
\text { i }\end{array}$ & $\begin{array}{l}\text { SENSOR } \\
\text { COMM, } \\
2011\end{array}$ & $\begin{array}{l}\text { Improving } \\
\text { DD to } \\
\text { reduce } \\
\text { average } \\
\text { energy }\end{array}$ & $\begin{array}{l}\text { If the network encounters a lot of decay } \\
\text { with the addition of locations, the delivery } \\
\text { rate will get worse. Using the limited } \\
\text { Directed Diffusion, we tried to increase the } \\
\text { network lifetime by reducing energy } \\
\text { consumption. }\end{array}$ \\
\hline 5. & $\begin{array}{l}\text { Apidach } \\
\text { Boorana } \\
\text { wong }\end{array}$ & $\begin{array}{l}\text { 2009,IEE } \\
\mathrm{E}\end{array}$ & $\begin{array}{l}\text { Modifying } \\
\text { the original } \\
\text { directed } \\
\text { diffusion to } \\
\text { reduce the } \\
\text { number of } \\
\text { the } \\
\text { exploratory } \\
\text { Data } \\
\text { messages. }\end{array}$ & $\begin{array}{l}\text { The experiment results indicate that the } \\
\text { proposed EDR algorithm can effectively } \\
\text { reduce the protocol signaling overhead on } \\
\text { directed diffision routing. }\end{array}$ \\
\hline 6. & \begin{tabular}{|l|} 
Ingrid \\
Teixeira
\end{tabular} & SBT, 2004 & \begin{tabular}{|l} 
Improving \\
network \\
energy \\
consumptio \\
$\mathrm{n}$
\end{tabular} & $\begin{array}{l}\text { Modifies the directed diffusion (DD) } \\
\text { protocol so that it spreads the traffic over } \\
\text { the network without maintaining multiple } \\
\text { paths. }\end{array}$ \\
\hline 7. & Jie Chen & $\begin{array}{l}2008 \text {,IEE } \\
\text { E }\end{array}$ & $\begin{array}{l}\text { Network } \\
\text { performanc } \\
\text { e }\end{array}$ & $\begin{array}{l}\text { We proposed a multipath routing protocol to } \\
\text { improve the performance of the wireless } \\
\text { sensor networks, which is called EEOR. }\end{array}$ \\
\hline 8. & $\begin{array}{l}\text { Wendi } \\
\text { Heinzelm } \\
\text { an }\end{array}$ & $\begin{array}{l}\text { University } \\
\text { of } \\
\text { Rochester }\end{array}$ & $\begin{array}{l}\text { Sleeping } \\
\text { Multipath } \\
\text { Routing }\end{array}$ & $\begin{array}{l}\text { Sleeping Multipath Routing to trade off } \\
\text { between reliability and lifetime in wireless } \\
\text { sensor networks. NS-2 simulation results } \\
\text { show that Sleeping Multi-path Routing } \\
\text { significantly prolongs the network lifetime, } \\
\text { and it can trade off between reliability and } \\
\text { lifetime by controlling the number of } \\
\text { activated disjoint paths. }\end{array}$ \\
\hline 9. & \begin{tabular}{|l|} 
CUI \\
Yanrong
\end{tabular} & $\begin{array}{l}2007, \\
\text { IEEE }\end{array}$ & $\begin{array}{l}\text { Improved } \\
\text { DD } \\
\text { protocol }\end{array}$ & $\begin{array}{l}\text { Simulation results show that with the } \\
\text { network scale increasing, the energy } \\
\text { consumptions and data delivery delay of } \\
\text { IDD and DD are increasing, but compared } \\
\text { with DD, IDD has higher efficient energy } \\
\text { and lower delay, and can pro long the } \\
\text { lifetime of wireless networks. }\end{array}$ \\
\hline $\begin{array}{l}10 \\
. .\end{array}$ & Jian Wan & $\begin{array}{l}2008 \text {,IEE } \\
\mathrm{E}\end{array}$ & $\begin{array}{l}\text { An } \\
\text { Efficient } \\
\text { Gradient } \\
\text { Mechanism } \\
\text { of Directed } \\
\text { Diffusion }\end{array}$ & $\begin{array}{l}\text { Simulation results show that the improved } \\
\text { gradient mechanism achieves better energy } \\
\text { balance and lower delay for data transfer } \\
\text { than DD in coordinative conditions. It can } \\
\text { help to extend the entire network lifetime. }\end{array}$ \\
\hline 11 & $\begin{array}{l}\text { Zhu } \\
\text { Xiangbin }\end{array}$ & $\begin{array}{l}2007, \text { IEE } \\
\mathrm{E}\end{array}$ & $\begin{array}{l}\text { Improved } \\
\text { Energy } \\
\text { Aware } \\
\text { Directed } \\
\text { Diffusion } \\
\text { Algorithm }\end{array}$ & $\begin{array}{l}\text { Improved algorithm achieves both energy } \\
\text { efficiency and lower node death ratio so it } \\
\text { extend network lifetime by send } \\
\text { reinforcement message and enhances the } \\
\text { network reliability by maintaining } \\
\text { remaining energy distribution relatively } \\
\text { uniform among sensor nodes. }\end{array}$ \\
\hline 12 & Jiayi Liu & $\begin{array}{l}\text { 2010,IEE } \\
\mathrm{E}\end{array}$ & $\begin{array}{l}\text { Fault } \\
\text { Tolerant } \\
\text { and } \\
\text { Storage } \\
\text { Efficient } \\
\text { Directed } \\
\text { Diffusion } \\
\text { (FTSDD) }\end{array}$ & $\begin{array}{l}\text { Using this new algorithm, the flooding of } \\
\text { interest, creating hop count and sending } \\
\text { exploration and data are more reliable in the } \\
\text { networks. The proposed algorithm can } \\
\text { reduce data loss rate and increase the } \\
\text { throughput of networks. }\end{array}$ \\
\hline
\end{tabular}




\begin{tabular}{|c|c|c|c|c|}
\hline 13 & Chen Hui & $\begin{array}{l}2009, \text { IEE } \\
\text { E }\end{array}$ & $\begin{array}{l}\text { Improveme } \\
\text { nt of } \\
\text { Directed } \\
\text { Diffusion } \\
\text { Protocol } \\
\text { Based on } \\
\text { Data } \\
\text { Aggregatio } \\
\text { n }\end{array}$ & $\begin{array}{l}\text { The accuracy and real-time properties of the } \\
\text { data is guaranteed by the introduction of } \\
\text { cascading timeouts, which also balances } \\
\text { data flows on different transmission paths. } \\
\text { The effectiveness of the routing is proved } \\
\text { by the simulation. }\end{array}$ \\
\hline 14 & $\begin{array}{l}\text { Kenan } \\
\text { Casey }\end{array}$ & $\begin{array}{l}\text { 2008,IEE } \\
\text { E }\end{array}$ & $\begin{array}{l}\text { A real-time } \\
\text { communica } \\
\text { tion } \\
\text { protocol } \\
\text { for directed } \\
\text { Diffusion } \\
\text { (RTDD) } \\
\end{array}$ & $\begin{array}{l}\text { RTDD is a simple protocol which provides } \\
\text { significant enhancements to directed } \\
\text { diffusion. Most notably, RTDD allows } \\
\text { diffusion to support applications such as } \\
\text { sense and response systems, in which timely } \\
\text { communication is essential. }\end{array}$ \\
\hline 15 & $\begin{array}{l}\text { Roberto } \\
\text { DiPietro }\end{array}$ & $\begin{array}{l}\text { 2003,IEE } \\
\text { E }\end{array}$ & $\begin{array}{l}\text { LKHW-A } \\
\text { Directed } \\
\text { Diffusion } \\
\text { Based } \\
\text { Secure } \\
\text { Multicast } \\
\text { Scheme for } \\
\text { Wireless } \\
\text { Sensor } \\
\text { Networks }\end{array}$ & $\begin{array}{l}\text { The scheme is independent of the } \\
\text { underlying key management architecture. In } \\
\text { terms of efficiency, the rekeying overhead } \\
\text { in terms of energy cannot be concretely } \\
\text { quantified without considering the topology, } \\
\text { but it is found to be approximately } \\
\text { logarithmic to the group size. }\end{array}$ \\
\hline
\end{tabular}

\section{CONCLUSION}

Directed Diffusion is a reactive protocol which creates route based on need and the sensed data that's stored in attribute value pairs. This paper represents the introduction of Directed Diffusion protocol (which is used in wireless sensor network), architecture, variants, issues related with it and its current developments. Directed diffusion simulation can be done by network simulator tool ns-2 [9]. This paper would provide us more and easy knowledge about functionality of Directed Diffusion protocol. Attacks on DD also discussed in this paper and can be minimized in future work. In current developments we included previous work of 15 papers, which shows author name, its publication year, effect field and description of work is discussed in brief. There are several lessons we can draw from our preliminary evaluation of diffusion. First, directed diffusion has the potential for significant energy efficiency. Second, diffusion mechanisms are stable under the range of network dynamics considered in this paper. Finally, for directed diffusion to achieve its full potential, careful attention has to be paid to the design of sensor radio MAC layers. This paper would be helpful to work and study about DD for future researches.

\section{REFERENCES}

[1] A.A. Ahmed, H. Shi and Y. Shang," A survey on network protocols for wireless sensor networks", Information Technology: Research and Education (ITRE 2003), Aug.2003.

[2] C.Intanagonwiwat, R.Govindan, D. Estrin, J. Heidemann. "Directed diffusion for wireless sensor networking", IEEE/ACM Transaction on networking, 2003, 11(1):216.

[3] Nazia Perwaiz, Muhammad Younas Javed, "A Study on Distributed Diffusion and its Variants," Proceedings of $200912^{\text {th }}$ International Conference on Computer and Information Technology (ICC IT 2009)21-23 December, 2009.

[4] Shousheng Zhao, Fengqi Yu, Baohua Zhao," An Energy Efficient Directed Diffusion Routing Protocol",2007 International Conference of Computational Intelligence and Security, pp-1068.

[5] Kenan Casey, Raghu Neelisetti, and Alvin Lim, "RTDD: A Real-Time Communication Protocol for Directed Diffusion” pp. 2854 IEEE Communications Society publication in the WCNC 2008 proceedings.

[6] S.Ganeriwal, R.Kumar, and M.B. Srivastava, "Timingsync protocol for sensor networks," in SenSys '03: Proceedings of the 1st international conference on Embedded networked sensor systems. NewYork, NY, USA: ACM Press, 2003, pp. 138-149

[7] C.Intanagonwiwat, R.Govindan and D.Estrin. "Directed diffusion: A scalable and robust communication paradigm for sensor networks." In Proceedings (MOBICOM), Boston, Massachusetts, August 2000.

[8] Wendi Rabiner Heinzelman, Anantha Chandrakasan and Hari Balakrishnan"Energy-Efficient Communication protocol for wireless sensor Networks" Proc. 33rd Hawaii Int'l. Conf. Sys. Sci., Jan. 2000.

[9] "Ns-2 network simulator," http://www.isi.edu/nsnam/ns/, 1998. 